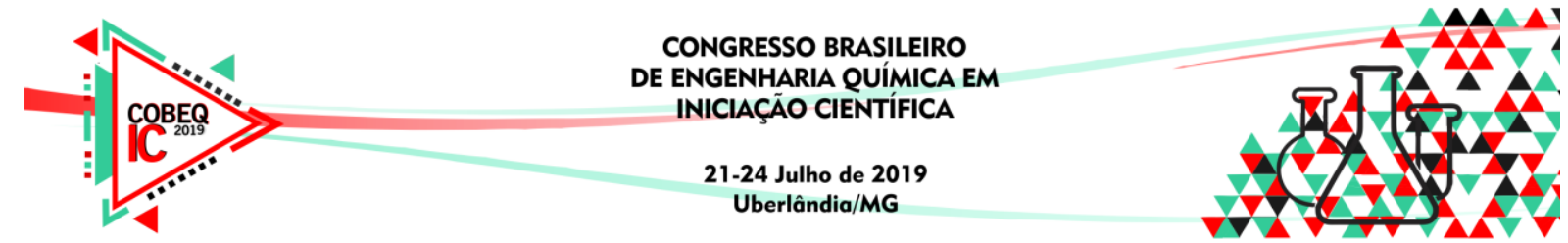

\title{
DIMENSIONAMENTO E AVALIAÇÃO HIDRODINÂMICA DE UM BIORREATOR DO TIPO AIRLIFT UTILIZANDO COMO FASE SÓLIDA PÓ DE SABUGO DE MILHO
}

\author{
J. F. TITATO ${ }^{1}$, B. F. IZIDORO ${ }^{2}$, M. SCONTRI ${ }^{2}$, A. V. DE PAULA ${ }^{2}$ e M. O. CERRI ${ }^{1}$ \\ ${ }^{1}$ Universidade Estadual Paulista “Júlio de Mesquita Filho”, Departamento de Bioprocessos e \\ Biotecnologia \\ ${ }^{2}$ Universidade Estadual Paulista "Júlio de Mesquita Filho", Departamento de Bioprocessos e \\ Biotecnologia \\ E-mail para contato: jeine.titato@gmail.com
}

\begin{abstract}
RESUMO - Biorreatores do tipo airlift se destacam por apresentar boa mistura, transferências de massa e calor eficientes, como também baixa taxa de cisalhamento devido a sua forma de escoamento, sendo uma ótima alternativa para reações com enzimas imobilizadas. Já o pó de sabugo de milho é um resíduo agroindustrial de baixo valor agregado que pode ser utilizado como suporte de imobilização enzimática. Tendo isso em vista, o objetivo deste trabalho foi dimensionar e confeccionar em material acrílico, um biorreator do tipo airlift com volume útil de $1 \mathrm{~L}$ e posteriormente avaliar seu desempenho hidrodinâmico variando-se a carga de sólidos a partir de $0,5 \%$ até um limite máximo, e a vazão de ar de 0,5 a 5 vvm. Foi observado que o reator apresenta boa mistura a partir da vazão de ar de 1vvm, e a carga de sólidos máxima obtida foi de 5\%.
\end{abstract}

\section{INTRODUÇÃO}

Biorreatores são utilizados pela humanidade desde a antiguidade, e ao longo dos anos foram sendo aperfeiçoados com o objetivo de melhorar a qualidade e aumentar a produção dos mais diversos produtos. O biorreator do tipo airlift se caracteriza por não apresentar partes móveis de forma que a circulação do meio é gerada pela gaseificação de fundo, fazendo com que a fase líquida seja impulsionada pelas bolhas que se movem de baixo para cima, retornando para baixo por uma região diferente da região de subida, dessa forma, este tipo de biorreator apresenta uma boa mistura, transferências de massa e calor eficientes, como também baixa taxa de cisalhamento, sendo uma ótima alternativa para reações com enzimas imobilizadas (CERRI, 2009). A escolha de um biorreator que apresente uma fluidodinâmica apropriada para determinado tipo de cultivo é essencial para a homogeneização do meio e consequentemente para a eficiência da reação, de forma a proporcionar um melhor rendimento (FU et al, 2003). A viscosidade do fluido, assim como, o tipo de a agitação, temperatura, vazão de ar ou fluido, entre outros fatores, influenciam na qualidade da mistura, e é essencial que todos os pontos internos do biorreator apresentem o mesmo grau de mistura, 


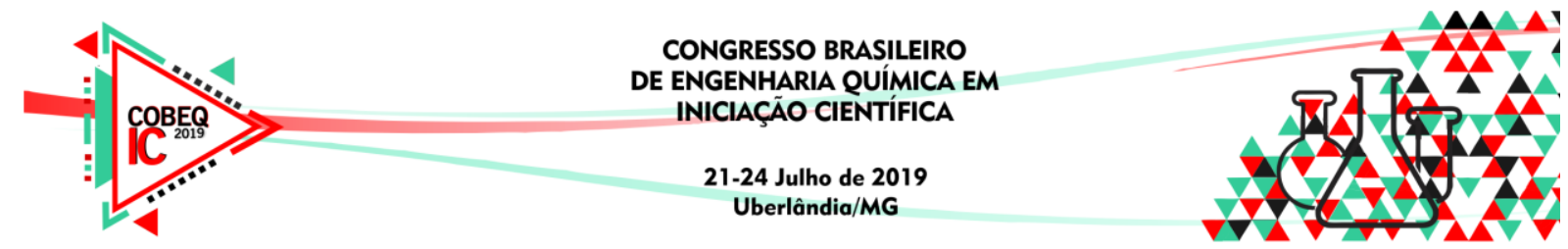

de forma a evitar zonas de estagnação e promover uma boa homogeneização (WANG et al, 2002). Para garantir que isto ocorra, é possível monitorar alguns parâmetros como o tempo de mistura, tempo de circulação e a retenção gasosa (WANG et al, 2002).

Neste contexto, o presente trabalho tem por objetivo dimensionar e confeccionar o reator airlift em material acrílico, para que apresente o volume útil de $1 \mathrm{~L}$, e analisar seu desempenho utilizando água, ar e pó de sabugo de milho. A utilização do pó de sabugo de milho se faz interessante tanto do ponto de vista comercial como ambiental, pois se trata de um resíduo agroindustrial de baixo valor agregado, podendo ser utilizado em trabalhos futuros como suporte para imobilização enzimática (BASSAN et al., 2016).

\section{MATERIAIS E MÉTODOS}

\subsection{Determinação do Tempo de Circulação}

O tempo de circulação foi determinado com o auxílio de uma esfera de polipropileno de diâmetro de $9,77 \mathrm{~mm}$, com a mesma densidade da água e um rotâmetro (GFC17 AALBORG®). O biorreator foi preenchido com água até que se atingisse o volume útil e então foi submetido a uma vazão de ar comprimido. O tempo necessário para que a esfera completasse 10 voltas dentro do biorreator foi cronometrado, e em seguida, esse tempo foi dividido por 10 para a obtenção do tempo médio de 1 volta. $\mathrm{O}$ experimento foi realizado variando-se a carga de sólidos de 0 a $6 \%$ (m/v; massa de pó de sabugo e volume útil do reator, respectivamente) e a vazão de ar de 0,5 a 5 vvm.

Determinação da carga de sólidos máxima: Foram adicionadas porcentagens do pó de sabugo de milho, 0,5 a $6 \%(\mathrm{~m} / \mathrm{v})$, e alterando-se a vazão de ar (0,5 a $5 \mathrm{vvm})$ até que houvesse a obstrução da circulação da mistura dentro do biorreator.

\subsection{Determinação do Tempo de Mistura}

O tempo de mistura foi determinado por meio de um ensaio tipo pulso de $\mathrm{pH}$ utilizando-se uma solução de $\mathrm{NaOH} 5 \mathrm{M}$, uma solução de $\mathrm{HCl} 5 \mathrm{M}$ e indicador de $\mathrm{pH}$ fenolftaleína. $\mathrm{O}$ reator foi preenchido com água até que se atingisse seu volume útil, foram adicionadas 3 gotas da solução de fenolftaleína e $500 \mu \mathrm{l}$ da solução de $\mathrm{NaOH} 5 \mathrm{M}$, e então cronometrou-se o tempo que a mistura levou para adquirir completamente a coloração rosada, indicando que foi homogeneizada. $\mathrm{O}$ experimento foi realizado em triplicata, variando-se as vazões de ar de 0,5 a 5 vvm, e a carga de sólidos de 0,5 a $5 \%(\mathrm{~m} / \mathrm{v})$.

\section{RESULTADOS E DISCUSSÃO}

\subsection{Dimensionamento do Biorreator}

O dimensionamento foi realizado de acordo com as relações apresentadas CERRI (2009). A tabela 1 compara as medidas obtidas para cada uma das partes do reator. 


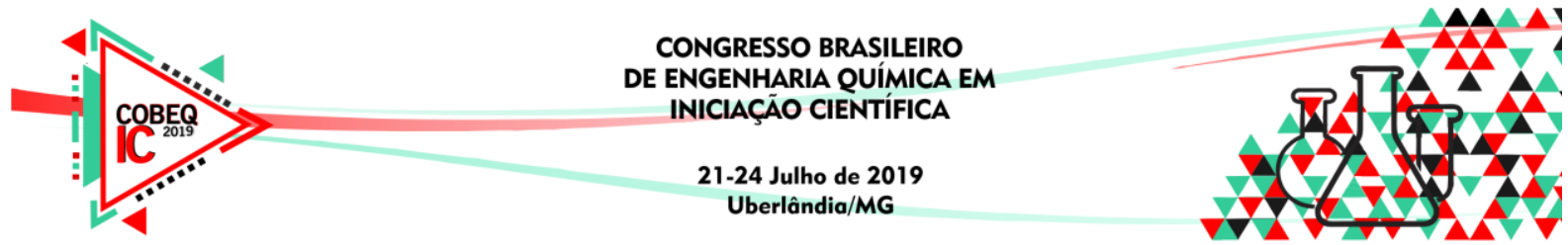

Tabela 1 - Medidas obtidas por CERRI (2009), por cálculo (teórico) e medidas do reator fabricado (real), respectivamente

\begin{tabular}{|c|c|c|c|}
\hline Dimensões & $\begin{array}{c}\text { Reator 2L } \\
\text { (mm), (CERRI, } \\
\text { 2009). }\end{array}$ & $\begin{array}{c}\text { Reator 1L } \\
\text { (teórico), (mm) }\end{array}$ & $\begin{array}{c}\text { Reator 1L } \\
\text { (real), (mm) }\end{array}$ \\
\hline H1 & 32 & 25,46 & 32 \\
\hline H2 & 33 & 25,46 & 30 \\
\hline H3 & 262 & 203,67 & 205 \\
\hline H4 & 327 & 254,59 & 267 \\
\hline H5 & 450 & 339,45 & 336 \\
\hline De1 & 90 & 70,72 & 75 \\
\hline De2 & 100 & 80,72 & 80 \\
\hline Di2 & 55 & 42,43 & 44 \\
\hline Di1 & 65 & 46,43 & 49 \\
\hline H4/De1 & 3,63 & 3,60 & 3,56 \\
\hline Ad/As & 1,68 & 1,58 & 1,67 \\
\hline Di2/De1 & 0,61 & 0,60 & 0,59 \\
\hline
\end{tabular}

As medidas do reator real apresentaram diferenças em relação às medidas teóricas, isso implicou na mudança do volume útil de $1 \mathrm{~L}$ para 1,07L. Além disso, as relações H4/De1, Ad/As e Di2/De1 apresentaram pequenas variações, porém os valores se mantiveram próximos aos valores teóricos e aos obtidos por CERRI (2009) para o reator de 2L. Após finalizada a etapa de dimensionamento, o biorreator foi confeccionado em material acrílico como apresentado na figura 1 .

Figura 1 - a) parte inferior do reator com parafusos, anéis de vedação e difusor de ar, b) reator montado por completo com todas as peças

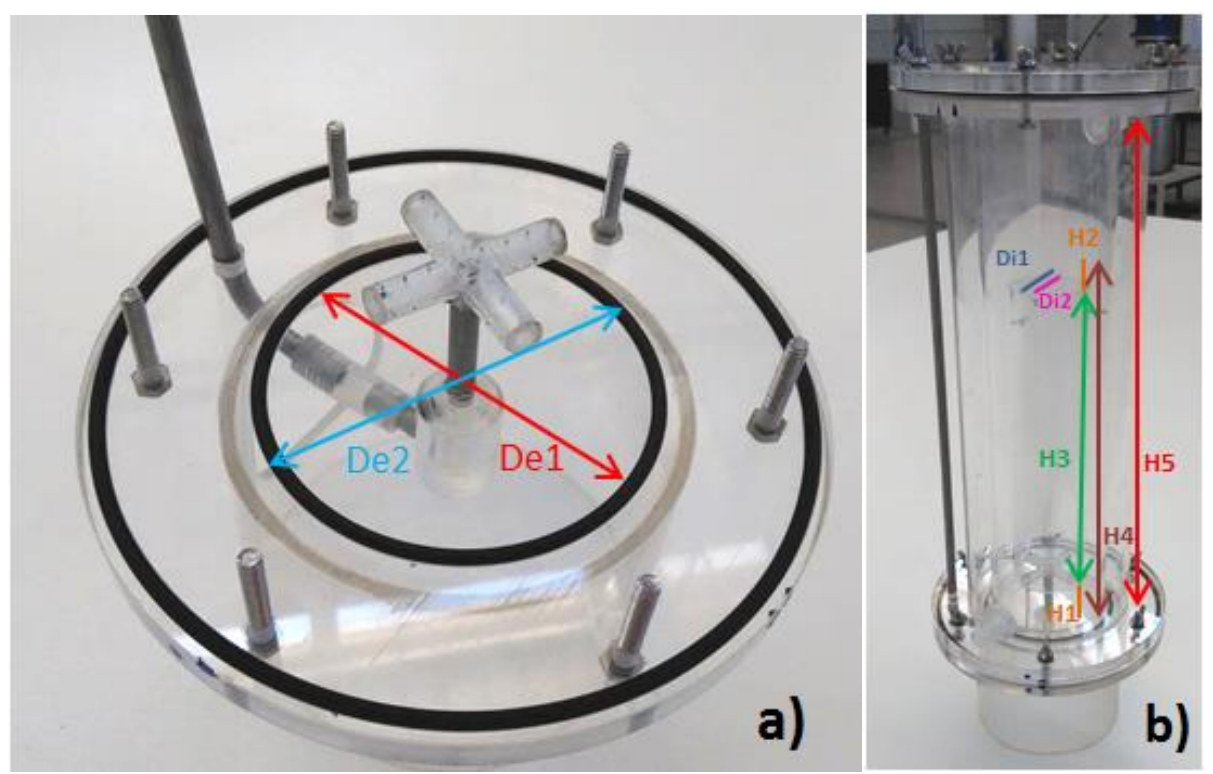




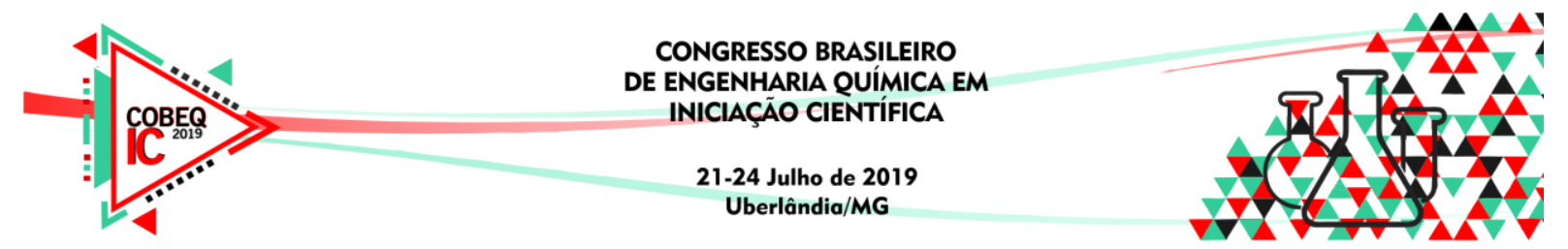

\subsection{Tempo de Circulação}

A tabela 2 apresenta os valores de tempo de circulação obtidos experimentalmente. A $\mathrm{U}_{\mathrm{GS}}$ (velocidade superficial do gás na região de subida) foi calculada a partir da razão da vazão de ar pela área da região de subida do gás como descrito por CERRI (2009). O valor da área obtido para a região de subida do gás para o reator real é de $1520,531 \mathrm{~mm}^{2}$.

Tabela 2 - Valores de tempo de circulação obtidos variando-se a vazão de ar e a carga de sólidos, para o reator airlift.

\begin{tabular}{|c|c|c|c|c|c|c|c|c|c|}
\hline \multicolumn{10}{|c|}{ Tempo de Circulação (1 volta) (Airlift_H2O)(s) } \\
\hline $\begin{array}{c}\text { Vazão } \\
\text { de ar } \\
(\mathbf{v v m})\end{array}$ & $\begin{array}{c}\mathbf{U}_{\mathbf{G S}} \\
(\mathbf{m} / \mathbf{s})\end{array}$ & $\mathbf{0 \%}$ & $\mathbf{0 , 5 \%}$ & $\mathbf{1 \%}$ & $\mathbf{2 \%}$ & $\mathbf{3 \%}$ & $\mathbf{4 \%}$ & $\mathbf{5 \%}$ & $\mathbf{6 \%}$ \\
\hline $\mathbf{0 , 5}$ & $\mathbf{0 , 0 0 5}$ & 6,5 & 8,4 & 6,8 & 6,4 & 6,6 & 7,8 & 8,0 & - \\
\hline $\mathbf{1}$ & $\mathbf{0 , 0 1 1}$ & 4,6 & 5,3 & 6,0 & 5,6 & 6,2 & 6,2 & 6,4 & 6,3 \\
\hline $\mathbf{2}$ & $\mathbf{0 , 0 2 2}$ & 4,1 & 4,1 & 4,3 & 4,8 & 5,8 & 4,9 & 4,7 & 5,3 \\
\hline $\mathbf{3}$ & $\mathbf{0 , 0 3 3}$ & 2,9 & 3,4 & 3,2 & 3,4 & 5,0 & 4,6 & 4,5 & 4,7 \\
\hline $\mathbf{4}$ & $\mathbf{0 , 0 4 4}$ & 2,9 & 3,0 & 3,1 & 3,6 & 4,0 & 4,2 & 4,0 & 4,1 \\
\hline $\mathbf{5}$ & $\mathbf{0 , 0 5 5}$ & 2,8 & 3,0 & 3,0 & 3,3 & 4,0 & 3,4 & 4,1 & 4,2 \\
\hline
\end{tabular}

É possível notar que os tempos de circulação diminuíram com o aumento da vazão de ar para todas as concentrações de pó de sabugo de milho, e entre 4 e $5 \mathrm{vvm}$ os valores de tempo tenderam a estabilidade, com excessão da concentração de $4 \%$. Já para o procedimento realizado apenas com água $(0 \%)$, o tempo se estabilizou entre 3 e $5 \mathrm{vvm}$. Um resultado semelhante foi obtido por CERRI (2009), devido a estabilização do tempo de circulação em $3 \mathrm{~s}$ a partir de um $\mathrm{U}_{\mathrm{GS}}$ de $0,035 \mathrm{~m} / \mathrm{s}$. Em geral, foi observado que para uma mesma vazão de ar, quanto maior a carga de sólidos maior o tempo de circulação. Para vazões de ar inferiores ou iguais a 0,5 vvm houve acúmulo de pó de sabugo de milho no fundo do reator evidenciando uma baixa homogeneização e a existência de zonas de estagnação. Isso ocorreu até mesmo para a menor carga de sólidos utilizada no experimento, 0,5\%. Para a carga de sólidos de $6 \%$ não foi possível medir o tempo de circulação na vazão de $0,5 \mathrm{vvm}$, pois a esfera permaneceu estagnada na parte superior do reator, porém, foi observado que embora a esfera não circulasse, o pó de sabugo ainda se movimentava e havia grande acúmulo do mesmo no fundo do reator.

\subsection{Tempo de Mistura}

Na tabela 3 são apresentadas as médias dos tempos obtidos experimentalmente. Os valores dos tempos de mistura apresentaram um comportamento semelhante aos dos tempos de circulação, que diminuíram de acordo com o aumento da vazão de ar para uma mesma carga de sólidos. 


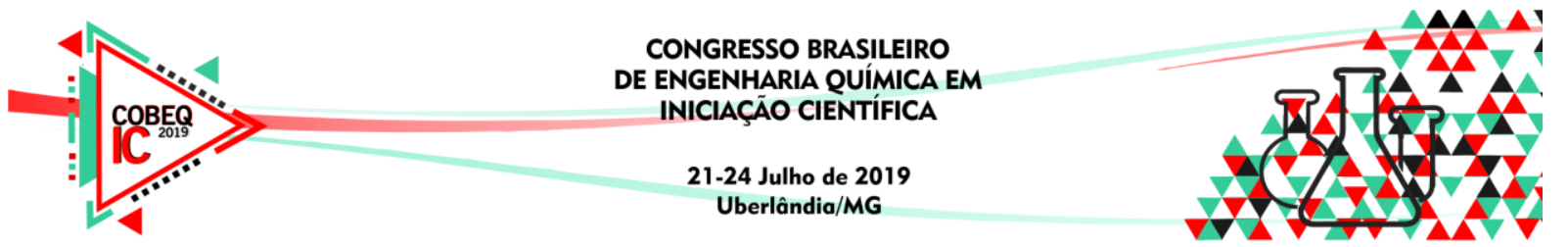

Tabela 3 - Valores de tempo de mistura obtidos para o reator airlift utilizando água e variando-se as vazões de ar e a carga de sólidos

\begin{tabular}{|c|c|c|c|c|c|c|c|c|}
\hline \multirow{2}{*}{$\begin{array}{c}\text { Vazão } \\
\text { de } \mathbf{a r} \\
(\mathbf{v v m})\end{array}$} & \multirow{2}{*}{$\begin{array}{c}\mathbf{U}_{\mathbf{G S}} \\
(\mathbf{m} / \mathbf{s})\end{array}$} & \multicolumn{7}{|c|}{ Tempo de Mistura (Airlift_H2O) (s) } \\
\cline { 3 - 9 } & & $\mathbf{0 \%}$ & $\mathbf{0 , 5 0 \%}$ & $\mathbf{1 \%}$ & $\mathbf{2 \%}$ & $\mathbf{3 \%}$ & $\mathbf{4 \%}$ & $\mathbf{5 \%}$ \\
\hline $\mathbf{0 , 5}$ & $\mathbf{0 , 0 0 5}$ & 6,00 & 7,47 & 7,00 & 6,33 & 7,70 & 6,87 & 5,75 \\
\hline $\mathbf{1}$ & $\mathbf{0 , 0 1 1}$ & 4,67 & 6,40 & 5,67 & 5,97 & 6,10 & 4,80 & 4,53 \\
\hline $\mathbf{2}$ & $\mathbf{0 , 0 2 2}$ & 3,83 & 4,83 & 5,00 & 4,77 & 4,67 & 4,53 & 3,53 \\
\hline $\mathbf{3}$ & $\mathbf{0 , 0 3 3}$ & 3,47 & 4,67 & 4,90 & 3,87 & 3,73 & 3,50 & 2,80 \\
\hline $\mathbf{4}$ & $\mathbf{0 , 0 4 4}$ & 3,70 & 5,67 & 4,83 & 4,13 & 3,57 & 3,60 & 3,07 \\
\hline $\mathbf{5}$ & $\mathbf{0 , 0 5 5}$ & 2,77 & 3,57 & 3,97 & 3,53 & 3,70 & 3,10 & 3,13 \\
\hline
\end{tabular}

Para as vazões de ar 0,5 a 2vvm e variando-se a carga de sólidos de 0,5\% a 3\%, os tempos permaneceram aproximadamente constantes e a partir de $4 \%$ os valores começaram a diminuir. A partir da carga de sólidos de 5\% não foi possível aferir os tempos de mistura com o método tipo pulso de $\mathrm{pH}$, pois a observação da mudança de coloração do meio foi impossibilitada pela quantidade de pó de sabugo de milho. ESPERANÇA et al., (2010), utilizou um biorreator airlift de capacidade de 2L, contendo água destilada, bagaço de cana de açúcar e ar, e foi relatado que a faixa de operação ótima se caracterizou por conter carga de sólidos de até $1 \%$ e vazão de ar igual ou superior a 32,1 L/min.

\section{CONCLUSÃO}

O reator mostrou-se apto a ser utilizado quando foi submetido as condições experimentais, apresentando boa homogeneização. Em geral, foi observado que para uma mesma vazão de ar, quanto maior a carga de sólidos maior o tempo de circulação. Os valores dos tempos de mistura apresentaram um comportamento semelhante aos dos tempos de circulação, que diminuíram de acordo com o aumento da vazão de ar para uma mesma carga de sólidos. A mínima vazão de ar para garantir a completa homogeneização do meio foi de $1 \mathrm{vvm}, \mathrm{U}_{\mathrm{GS}}$ de $0,011 \mathrm{~m} / \mathrm{s}$ e a carga de sólidos máxima foi de $5 \%$.

\section{NOMENCLATURA}

Ad: área da secçãotransversal da região de descida $\left(\mathrm{mm}^{2}\right)$

As: área da secçãotransversal da região de subida $\left(\mathrm{mm}^{2}\right)$

De1: diâmetro interno do tubo externo ( $\mathrm{mm})$

De2: diâmetro externo do tubo externo ( $\mathrm{mm})$

Di1: diâmetro externo do tubo concêntrico (mm) 


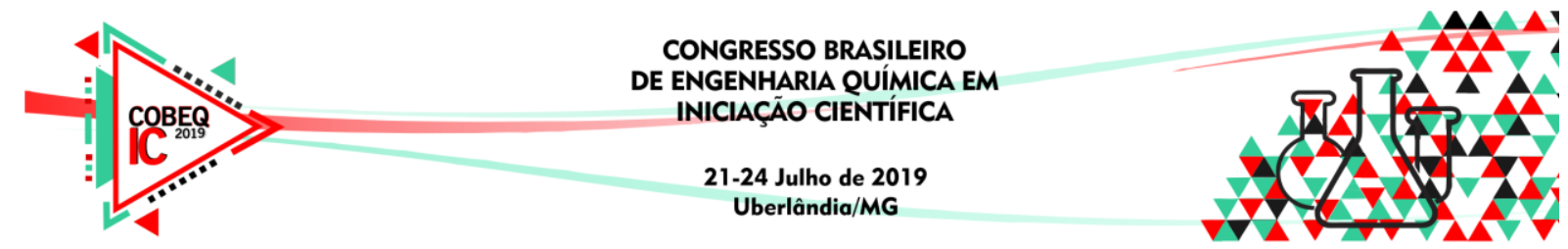

Di2: diâmetro interno do tubo concêntrico $(\mathrm{mm})$

H1: altura da base do reator até o tubo concêntrico (mm)

H2: altura do topo do tubo concêntrico até a altura de líquido (mm)

H3: altura do tubo concêntrico ( $\mathrm{mm})$

H4: altura de líquido (mm)

H5: altura interna total do reator $(\mathrm{mm})$

$\mathrm{U}_{\mathrm{GS}}$ : velocidade superficial do gás na região de subida $(\mathrm{m} / \mathrm{s})$

\section{AGRADECIMENTOS}

Os autores agradecem à Fundação de Amparo à pesquisa do Estado de São Paulo (FAPESP) - processo 2017/11482-7, ao Programa Institucional de Bolsas de Iniciação Científica e a Universidade Estadual Paulista "Júlio de Mesquita Filho", PIBIC/UNESP 46531, pelo apoio financeiro.

\section{REFERÊNCIAS}

BASSAN, C. J.; SOUZA, B. M. T.; PEIXOTO, G.; CRUZ, P. Z. C.; GALÁN, M. P, J.; VAZ, S. B .A.; GARRIDO, S.S.; FILICE, M.; MONTI, R. Immobilization of trypsin in lignocellulosic waste material to produce peptides with bioactive potencial from whey protein. Materials, v. 9, n. 5, 2016.

CERRI, M.O.. Hidrodinâmica e transferência de oxigênio em três biorreatores Airlift de circulação interna geometricamente semelhantes. 2009. 157p. Tese (Doutorado em Engenharia Química) - Universidade Federal de São Carlos, São Carlos, 2009.

ESPERANÇA, M.N.; FARINAS, C.S.; CERRI, M.O.; BADINO, A.C.; CUNHA, F.M.; ZANGIROLAMI, T.C.. Estudo da transferência de oxigênio em reator airlift contendo bagaço de cana de açúcar. XVIII Congresso Brasileiro de Engenharia Química. COBEQ, Foz do Iguaçu/PR, 2010.

FU, C. C.; WU, H. T.; LU, S. Y. Performance of Airlift Bioreactors with Net Draft Tube. Enzyme and Microbial Technology, 33: 332-342, 2003.

WANG, P. M.; HUANG, T. K.; CHENG, H. P.; CHIEN, Y. H.; WU, W. T., A Modified Airlift Reactor with High Capabilities of Liquid Mixing and Mass Transfer, J. Chem. Eng. Jpn. 35, 354-359, 2002. 